NBER WORKING PAPER SERIES

\title{
INTERGENERATIONAL FISCAL CONSTITUTIONS: HOW TO PROTECT FUTURE GENERATIONS USING LAND TAXES AND FEDERALISM
}

\author{
John P. Conley \\ Antonio Rangel \\ Working Paper 8394 \\ http://www.nber.org/papers/w8394 \\ NATIONAL BUREAU OF ECONOMIC RESEARCH \\ 1050 Massachusetts Avenue \\ Cambridge, MA 02138 \\ July 2001
}

We would like to thank Alan Auerbach, Doug Bernheim, Stephen Coate, Maxim Engers, Dennis Epple, Chad Jones, John Keenan, William Johnson, Jon Levin , Tom Nechyba, Klaus Nehring, Wallace Oates, Luis Rayo, Robert Rosenthal, Rob Schwab, Steve Sheffrin, Holger Sieg, Joaquim Silvestre, Jonathan Skinner, Steve Tadelis, Michael Waldman , and seminar participants at Berkeley, Cornell, Duke, NBER, University of Maryland, University of Virginia, and UCLA for useful discussions and comments. The views expressed herein are those of the authors and not necessarily those of the National Bureau of Economic Research.

(C) 2001 by John P. Conley and Antonio Rangel. All rights reserved. Short sections of text, not to exceed two paragraphs, may be quoted without explicit permission provided that full credit, including $\odot$ notice, is given to the source. 
Intergenerational Fiscal Constitutions: How to Protect Future Generations

Using Land Taxes and Federalism

John P. Conley and Antonio Rangel

NBER Working Paper No. 8394

July 2001

JEL No. D7, D9, H0, H2, H3, H4, H5, H6, H7

\begin{abstract}
$\underline{\text { ABSTRACT }}$
This paper studies how to design a fiscal constitution that, by capitalizing intergenerational spillovers into land values, is able to protect future generations from expropriation and to generate optimal investment in intergenerational public goods. In particular, we study how to accomplish these goals by changing two dimensions of the fiscal constitution: (1) the level of government to which different types of intergenerational public goods are assigned, and (2) the tax base of the different jurisdictions. We show that the instruments required to generate capitalization of the intergenerational spillovers depend on the type of the spillover. Land taxation is the essential instrument for policies that mostly generate fiscal spillovers, such as debt and public infrastructure. By contrast, interjurisdictional competition is the essential instrument for policies that mostly generate direct spillovers, such as irreversible environmental damages. Furthermore, we show that it is possible to design a fiscal constitution that generates full capitalization of fiscal spillovers, but in general, not one that generates full capitalization of direct spillovers.
\end{abstract}

John P. Conley

Department of Economics

University of Illinois

jpconley@uiuc.edu
Antonio Rangel

Department of Economics

Stanford University

and NBER

rangel@leland.stanford.edu 


\section{Introduction}

Governments make decisions that affect the well-being of future generations. In particular, they issue debt that is repaid by future generations and decide how much to invest in intergenerational public goods (IPGs). Some IPGs, such as public infrastructure and environmental preservation, generate benefits for present and future generations. Others, such as pure R\&D, generate benefits mostly for future generations.

Given that public policy is made by present generations, the following two problems arise when they do not fully internalize the well-being of future generations: (1) present generations have an incentive to use debt to expropriate future generations, and (2) present generations have a tendency to under-invest in IPGs. Since the long term well-being of a society depends on its ability to generate sufficient investment in future generations, this creates an important problem in institutional design.

When generations are selfish, as we assume in this paper, ${ }^{1}$ any institution that solves this problem must find a mechanism to induce present generations to internalize the well-being of future generations. As it has been pointed out in the literature ${ }^{2}$, land provides such a mechanism: current generations own the land stock of the economy and thus care about the effect of public policy on land prices. ${ }^{3}$

This paper studies how to design a fiscal constitution that, by capitalizing intergenerational spillovers into land values, is able to protect future generations from expropriation and to generate optimal investment in IPGs. We focus on how to achieve these goals by changing two dimensions of the fiscal constitution: (1) the level of government to which different types of IPGs are assigned, and (2) the tax base of the different jurisdictions. We compare the ability of the following four institutions to generate capitalization of intergenerational spillovers: a centralized system with land taxation, a centralized system with income taxation, a federal

\footnotetext{
${ }^{1}$ This is the benchmark case for the types of problems studied here and provides the hardest testbed for a fiscal constitution. A more realistic assumption would be to assume that agents exhibit paternalistic (non-dynastical) altruism: agents care about the level of IPGs and debt passed to future generations, but not about their welfare. However, paternalistic altruism by itself would not eliminate the problem: present generations would still need institutional incentives to fully internalize the well-being of future generations. (See Altonji, Hayashi, and Kotlikoff $(1992,1997)$ and Rangel (2001)).

${ }^{2}$ See Oates and Schwab (1988,1996), Glaeser (1996), Sprunger and Wilson (1998), and Brueckner and Joo (1991).

${ }^{3}$ Other assets, like stocks, are also traded across generations. In section Section 3.1 we describe the properties that make land an ideal asset to deal with these problems.
} 
system with land taxation, and a federal system with income taxation.

An alternative to the institutions studied here would be a fiscal constitution that fully specifies, in advance, the amount of debt and investments in IPGs that must be made in every period and state of the economy. However, such a constitution is not feasible. There exists a significant amount of uncertainty about the future and as a result the sequence of optimal investments is not known in advance. A good fiscal constitution addresses this fundamental incompleteness by placing constraints on how decisions are made and how the government is financed.

The contribution of this paper is three-fold. First, we show that to design a fiscal constitution that protects future generations it is important to distinguish between fiscal spillovers and direct spillovers. A policy generates a fiscal spillover if it affects the budget constraint of future governments. For example, the debt increases the amount of revenue that has to be raised by future governments, but has no other effects. By contrast, a policy generates a direct spillover if it affects the technology set of future generations. Irreversible environmental damages, like the extinction of species, are an example of this type of spillover.

Second, we show that land taxation is the essential instrument to generate full capitalization of fiscal spillovers. Full capitalization of fiscal spillovers, including the debt, arises in both centralized and federal systems as long as all intergenerational expenditures are financed with land taxes. By contrast, full capitalization fails in both cases if expenditures are financed with income taxes.

Third, we show that interjurisdictional competition is the essential instrument to generate the capitalization of direct spillovers. For these policies, interjurisdictional competition generates capitalization effects that do not arise without decentralization (or at the state level in the absence of mobility). Furthermore, the advantage of decentralization for direct spillovers does not depend on the choice of the tax base. Nevertheless, with a finite and small number of jurisdictions full capitalization of direct intergenerational spillovers typically does not take place. This stands in sharp contrast to the case of fiscal spillovers, where full capitalization is possible.

There is a large body of literature on the design of fiscal constitutions. ${ }^{4}$ It has focused on intragenerational and static aspects of the problem like the role of heterogeneity in preferences, mobility, returns to scale in production, interjurisdic-

\footnotetext{
${ }^{4}$ See Oates (1999), Rubinfeld (1987), and Wildasin (1986) for excellent reviews of the literature. See also Inman and Rubinfeld (1996).
} 
tional spillovers, local informational advantages, experimentation, and asymmetries between local and central politics. By contrast, this paper focuses on intergenerational and dynamic issues. ${ }^{5}$

A number of papers have also studied the design of intergenerational fiscal constitutions. Most prominently, Oates and Schwab (1988,1996), Glaeser (1996), and McKinnon and Nechyba (1997) have argued that interjurisdictional competition is necessary to protect future generations. In their view, the ability to escape negative spillovers by moving to other jurisdictions is the central mechanism for protecting future generations. For example, Oates and Schwab (1996, p.327) state that: "The capitalization of any changes in the values of local amenities into property values provides a powerful incentive for current residents in a jurisdiction to take into account the effects of their decisions on future residents. The disciplinary force provided by such capitalization is absent at the national level, for its source is the mobility of individuals across jurisdictions. It is thus quite possible that decentralized decision making on certain environmental issues provides more protection for the interests of future generations than does a more centralized system". Similarly, Glaeser (1996, p.100) states that: "Property values do not reflect amenities on a nation-wide level nearly as clearly as they do on the local level, because the migration costs between countries are so much higher than the migration costs between jurisdictions."

In this paper we arrive at a different conclusion. First of all, we show that land taxes provide an alternative mechanism for capitalizing fiscal spillovers. Not only that, we show that full capitalization of fiscal spillovers arises with land taxation both in centralized and decentralized systems, but in general, not in a decentralized system with income taxation. Thus, land taxation, and not interjurisdictional competition, is the essential mechanism for the capitalization of fiscal spillovers. This is important because many IPGs that generate significant amounts of fiscal spillovers such as public infrastructure and R\&D - also exhibit economies of scale and generate

\footnotetext{
${ }^{5}$ The following papers also develop dynamic models of federal systems. Wildasin and Wilson (1996) develop a dynamic model of land-value-maximizing local governments and show that it generates inefficient levels of intragenerational public goods. Sprunger and Wilson (1998) study the capitalization of intergenerational spillovers in a dynamic model. They study pure federal systems in a partial equilibrium framework in which there is full capitalization of the spillovers. They show that the introduction of asymmetric information between residents and outsiders can eliminate the full capitalization result, leading to under or over-investment in IPGs. Brueckner and Joo (1991) study how capitalization effects influence how residents vote on local elections. As we assume in this paper, they show that agents are not pure property value maximizers, but also care about the taxes that they pay and their own consumption of public goods.
} 
interjurisdictional spillovers. If the insights from these papers were correct, there would be no hope of designing a fiscal constitution that generates optimal provision of these programs: there would be an inescapable conflict between the provision of intergenerational incentives and the basic principle of fiscal decentralization, which says that programs should be allocated to the lowest jurisdiction that encompass all of the interjurisdictional spillovers. This is also important because, if decentralization was the only institution capable of stopping intergenerational expropriation through the debt, then restrictions on the federal government's ability to raise debt would be necessary. In addition, interjurisdictional competition does play a role in the capitalization of direct spillovers such as irreversible environmental damage. But even then the intergenerational case for decentralization needs to be qualified: full capitalization is typically not possible for these types of policies.

Two essential factors explain why we arrive at different conclusions than the previous literature. First, previous studies do not consider the case of centralized institutions with land taxation. Second, and most important, previous studies work in a partial equilibrium framework by assuming that there is an infinite number of jurisdictions. The assumption of partial equilibrium is not innocuous in this context: with an infinite number of jurisdictions decentralization generates full capitalization of all intergenerational spillovers regardless of the tax base. By contrast, in the empirically relevant case of a finite and small number of jurisdictions, the choice of the tax base becomes important and full capitalization of direct intergenerational spillovers is no longer possible.

Several other papers are related to the issues studied here. Rangel (2001) ${ }^{6}$ studies the political economy of IPGs in a centralized system without land but with a richer set of public policies. He shows that present generations can be given an incentive to care about future generations through a political economy mechanism: there are equilibria in which present generations invest in IPGs such as long term environmental quality because otherwise they do not receive social security benefits in old age. The comparison in the performance of the two institutions is stark. There is a wide class of environments where a centralized system with land taxation generates optimal investment in future generations and no intergenerational redistribution, but a centralized system without land taxation does not. Kotlikoff and Rosenthal (1993) study the ability of a pure federal system with two jurisdictions

\footnotetext{
${ }^{6}$ See also Boldrin and Montes (1998).
} 


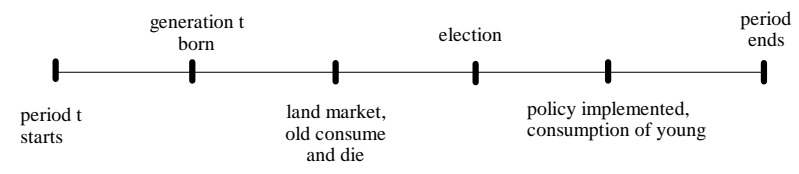

Figure 1: Timing of a period.

and income taxation to generate optimal investment in an IPG that only generates direct intergenerational spillovers. They derive a result similar to Theorem 7 in this paper. Finally, Epple and Schipper (1981), Inman (1982,1990), Johnson (1997), and Mumy (1978) have studied the extent to which expropriation of future generations can take place in a federal system through partially funded state and local public pension systems.

\section{Basic Model}

Consider a simple overlapping generations economy. Every period $t=1,2, \ldots$ a new generation of constant size $N$ is born and lives for two periods. Agents have identical preferences and economic opportunities. Every period there are three goods: a generic consumption good, land, and a public good. The consumption good is adopted as a numeraire. The amount of land in the economy is fixed and equal to $L$.

In the first period of life agents supply labor inelastically in exchange for a wage $w$. In the second period they do not work. Agents can borrow and save at the constant interest rate $r>0$. These assumptions hold in a closed economy that has an aggregate production function of the form $F(K, \lambda)=w \lambda+(1+r) K$, where $\lambda$ denotes labor and $K$ denotes capital, or in a small open economy in which capital is mobile, labor is not, and the world equilibrium interest rate is $r$.

The timing of a period is depicted in Figure 1. At the beginning of the period generation $t$ is born and receives its wage. Immediately after, a land market takes place in which the young purchase the land stock from the elderly. The elderly then consume all of their savings, including the proceeds from land sales, and die. Afterwards there is an election in which public policy for the period is decided. The period ends with the implementation of the chosen policies and the consumption and savings decisions of the young. 
Note that, since the elderly die at the beginning of the period, generations basically live for one period. In the second period they are alive just long enough to be able to sell the land and to consume their financial assets. This is the simplest demographic structure that gives rise to the intergenerational issues that we study. The crucial assumption is that agents care about the price at which they can sell their land in old age.

The preferences of generation $t$ are given by $U\left(c^{y}, c^{o}, l, G_{t}\right)$, where $c^{y}$ and $c^{o}$ denote their consumption when young and old, $l$ denotes their consumption of land, and $G_{t}$ denotes their consumption of intergenerational public goods during their youth. Since savings have no effect on wages or asset returns, agents are never liquidity constrained, and savings play no role in our analysis, we simplify the notation by working with the reduced form utility function:

$$
V\left(x, l, G_{t}\right) \equiv \max _{c^{y}, c^{o}} U\left(c^{y}, c^{o}, l, G_{t}\right) \text { s.t. } c^{y}+\frac{c^{o}}{1+r}=x .
$$

We assume that $V$ is twice continuously differentiable, strictly increasing, strictly concave, and satisfies the Inada conditions in all of the arguments. The following notation will be useful below. Let

$$
l(p, G) \equiv \arg \max _{l \geq 0} V(w-p l, l, G)
$$

We assume that $l(p, G)$ is decreasing in $p$, and strictly decreasing if $l>0$. We can think of $l(\cdot, G)$ as the demand function for land in a "static" economy where the level of public goods is given exogenously.

Every period $t$ the government makes two decisions: (1) how much to invest on intergenerational public goods (IPGs), denoted by $I_{t}$; and (2) how much debt to issue. Let $D_{t}$ denote the amount of debt at the end of the period. The government can borrow and lend at the fixed interest rate $r$. The only restriction on the government's ability to issue debt is a debt ceiling $D^{\max } \leq r w N$. Given this inequality, every generation has enough resources to service any amount of the debt that it receives from the previous generation. Another rationale for the debt ceiling is discussed in the next section.

Given these two decisions, and the debt inherited from the previous generation, the amount of taxes that must be raised in period $t$ is given by

$$
I_{t}+r D_{t-1}-\left(D_{t}-D_{t+1}\right)
$$


Note that the debt can be negative: the government could leave a trust-fund to future generations. Also, the debt inherited from previous generations imposes restrictions on present governments. For example, if $s_{D}=D^{\max }$ the government needs to raise at least $r D^{\text {max }}$ units of revenue.

As discussed in the introduction, it is important to distinguish between fiscal and direct intergenerational spillovers. A policy in period $t$ generates a fiscal spillover on generation $t+1$ if it affects the budget constraint of the government in period $t+1$. By contrast, a policy in period $t$ generates a direct spillover if it affects the technology of the economy in period $t+1$. The debt is an example of a government policy that only generates fiscal spillovers: each unit of inherited debt increases the revenue requirement of the government by $1+r$ units, but has no other effects. Irreversible environmental public goods, like the extinction of an species, are an example of direct spillovers.

We study two extreme types of IPGs: durable public goods (DPGs) and pure IPGs. The technology for DPGs in period $t$ is given by

$$
G_{t}=(1-\delta) G_{t-1}+I_{t}
$$

where $I_{t}$ denotes the amount of investment in period $t$, and $\delta \in(0,1)$ denotes the depreciation rate. Also, DPGs are reversible: a generation can choose to de-invest and consume the DPGs that it receives from the previous generation. Thus, $I_{t}$ can be negative, although it is bounded below: $I_{t} \geq-(1-\delta) G_{t-1}$. The key feature of DPGs is that they only generate fiscal spillovers. Since DPGs are reversible, each unit of DPGs produced in period $t$ increases the budget of the government in period $t+1$ by $1-\delta$ units. By contrast, the technology for pure IPGs is given by

$$
G_{t}=I_{t-1}
$$

The key feature of pure IPGs is that they only generate direct spillovers. In fact, pure IPGs are an extreme form of direct spillovers since the level of public goods consumed by generation $t$ is determined entirely by the previous generation. Most IPGs generate a mixture of fiscal and direct spillovers. DPGs and pure IPGs are useful conceptual devices because they allow us to isolate the ability of an institution to capitalize fiscal and direct spillovers.

At time $t=1$ there is also an old generation 0 that owns the land and only lives for that period. Let $G_{0}, I_{0}$, and $D_{0}$ denote the initial levels of IPGs, investment, and debt. We assume that $G_{0}=I_{0}=D_{0}=0$. 
There is a single branch of government and decisions are made by standard majority rule. When there are multiple jurisdictions, only the residents of the jurisdiction have the right to vote. Formally, we model the elections as a direct vote over the feasible policy space. However, given that agents are homogenous, this model of politics generates identical outcomes to any model of representative democracy in which Condorcet winners are selected whenever they exist. This includes the standard Downsian model of two party competition with binding campaign promises.

Given the stationary and symmetric nature of the model, we focus on symmetric Markovian allocations and equilibria. The state of the economy at the beginning of period $t$ is denoted by $s \equiv\left(s_{G}, s_{D}\right)$, where $s_{G}$ denotes the amount of IPGs received from the previous generation, and $s_{D}=D_{t-1}$. These two variables measure the amount of intergenerational spillovers generated by government policy. The formula for $s_{G}$ depends on the type of IPG. In the case of DPGs it is given by $s_{G} \equiv(1-\delta) G_{t-1}$. For pure IPGs it is given by $s_{G} \equiv I_{t-1}$. The inclusion of other variables in the state space, like savings, has no effect on our results.

In the following four sections we study four institutions that differ on the tax base that they use to finance intergenerational expenditures (land versus income taxes) and on their jurisdictional structure (centralization versus decentralization). A comparison of these institutions will allows us to understand the role that land taxes and federalism play on the capitalization of intergenerational spillovers, and thus on the provision of IPGs and on intergenerational expropriation.

\section{Centralized Systems with Land Taxation}

We start the analysis with the case of a centralized system where land is the only tax instrument: the government can only raise taxes using a proportional tax per-unit of land. ${ }^{7}$

Let $(I(s), D(s))$ denote a policy rule that specifies the level of investment and debt in state $s$. Given this policy rule, land taxes are given by

$$
\tau(s) \equiv \frac{I(s)+(1+r) s_{D}-D(s)}{L} .
$$

\footnotetext{
${ }^{7}$ Other methods of land taxation are possible; for example, taxes based on the market value of land, or taxes based on measures of land productivity. See Skinner (1991) for a discussion of different methods of land taxation and the difficulties in implementing them. For example, taxes on the market value of land require frequent assessments by the tax authority and involve large transaction costs. By contrast, taxes based on land area are easier to implement.
} 
The following objects are also useful. $\Delta(s) \equiv D(s)-s_{D}$ denotes the change in the government debt.

$$
G(s) \equiv\left\{\begin{array}{cc}
s_{G}+I(s) & \text { for DPGs } \\
s_{G} & \text { for pure IPGs }
\end{array}\right.
$$

denotes the amount of public goods consumed in state $s$. Finally, $\sigma(s)$ denotes the state that the policy rule generates at the beginning of period $t+1$ when the state in period $t$ is $s$.

The restriction to land taxation does not rule out intergenerational expropriation. For example, if $s_{D}=0$ the government could raise up to $D^{\max }$ units of revenue using debt and use it to give a transfer to current generations. The institution, however, places a restriction on the form of these transfers: all transactions between the government and the citizens must take place through the land tax (or subsidy).

DEFINITION 1: An equilibrium for a centralized system with land taxes is given by an allocation $(l(s), G(s))$, a policy rule $(I(s), D(s))$, and land prices $p(s)$ satisfying, for each $s:^{8}$

1. Land market equilibrium:

$$
l(s) \in \arg \max _{l \geq \mathbf{0}} V\left(w-l\left(p(s)+\tau(s)-\frac{p(\sigma(s))}{1+r}\right), l, G(s)\right) \text { and } l(s) N=L .
$$

2. Political equilibrium: Given the land holdings $l(s)$, the land prices $p(s)$, and the capitalization function $p(\cdot),(I(s), D(s))$ is a Condorcet winner in the set of feasible policies $\Pi(s) .^{9}$

The equilibrium notion requires rational expectations and sequential rationality. Individuals make decisions twice during their life: in the land market and in the election. At every stage, agents take as given present and future prices, and the

\footnotetext{
${ }^{8}$ Formally, an allocation also includes a description of the amount consumed by young and old in every state: $c^{y}(s)$ and $c^{o}(s)$. Given the objectives of the paper, and the assumptions of the model, we do not explicitly keep track of these variables. However, for any equilibrium, $c^{y}(s)$ and $c^{o}(s)$ are defined by:$$
\arg \max _{c^{y}, c^{o}} U\left(c^{y}, c^{o}, l(s), G(s)\right)
$$

s.t.

$$
c^{y}+\frac{c^{o}}{1+r}=w-l(s)\left(p(s)+\tau(s)-\frac{p(\sigma(s))}{1+r}\right)
$$

${ }^{9}$ A policy $(I, D)$ is feasible in state $s$ satisfies: (1) $I \geq-s$ in the case of DPGs, and $I \geq 0$ in the case of pure IPGs; (2) $0 \leq \tau l(s) \leq w-l(s)\left[p(s)-\frac{p(\sigma)}{1+r}\right]$, where $\tau$ and $\sigma$ are the land tax and the continuation state generated by $(I, D)$; and $(3) D \leq D^{\max }$.
} 
outcome of future elections. Consider the land market first. When an agent decides how much land to buy, he takes as given present and future land prices and the outcome of the election that will take place later in the period. The outcome of the election is important because it determines the land tax rate and the price at which the agent will be able to sell the land. In this sense, agents are price takers and policy takers. Land prices adjust to clear the land market in every state.

Now consider the election. Suppose, for example, that the public goods are DPGs. At this time land holdings are fixed. Agents take as given the capitalization function $p(\cdot)$, which gives the relationship between the outcome of the election and the price at which agents will be able to sell their land. Since agents are homogenous, the preferences of the representative agent over policies $(I, D)$ are given by

$$
V\left(w-l(s)\left[p(s)+\frac{(1+r) s_{D}+I-D}{L}-\frac{p\left((1-\delta)\left(I+s_{G}\right), D\right)}{1+r}\right], l(s), s_{G}+I\right) .
$$

The choice of investment affects their consumption of DPGs, but also the future price of land. The choice of debt only affects their life-time wealth. With homogenous agents, a Condorcet winner exists as long as there is a pair $(I(s), D(s))$ that maximizes (2) on the set of feasible policies $\Pi(s)$.

Note that an equilibrium specifies what happens at any possible state of the economy, even at states that are never reached in equilibrium. In particular, it specifies how land prices $p(s)$ change for any possible political decision. In this economy, this capitalization function is the only mechanism through which present generations internalize the spillovers that they generate on future generations.

\subsection{Fiscal Spillovers}

The following result characterizes the outcome of the centralized institution with land taxation when government policy only generates fiscal spillovers.

THEOREM 1: Consider an economy with DPGs, a centralized system with land taxation, and a debt ceiling $D^{\mathrm{max}} \leq \frac{L \bar{p}}{(1+r)} \cdot{ }^{10}$ This institution generates equilibria of the following form:

$$
\begin{gathered}
l(s)=\frac{L}{N} \text { and } G(s)=\bar{G}, \\
\tau(s)=\frac{\bar{G}}{L}-\frac{s_{G}}{L}+\frac{r s_{D}}{L}-\frac{\Delta_{D}(s)}{L},
\end{gathered}
$$

\footnotetext{
${ }^{10} \bar{p}$ is a constant given in (5).
} 
any feasible level of debt with $D(s) \leq D^{\max }$, and

$$
p(s)=\bar{p}+\frac{s_{G}}{L}-\frac{(1+r) s_{D}}{L} ;
$$

where $\bar{G}$ and $\bar{p}$ are uniquely defined constants.

The allocation generated by these equilibria is Pareto optimal.

Note a few interesting properties of these equilibria. First, there is full capitalization of fiscal spillovers. An additional unit of DPGs bequeathed to the next generation increases the value of the land stock by one unit; an additional unit of debt decreases it by $1+r$ units.

Second, given that there is full capitalization of fiscal spillovers, no intergenerational redistribution is possible: the life-time wealth of a generation is not affected by the actions of previous generations. DPGs are reversible and each unit of inherited DPGs increases the government budget by one unit. This is a transfer from generation $t$ to generation $t+1$. An extra unit of inherited DPGs also increases the value of the land stock by one unit. Since the trading of land generates a transfer from generation $t+1$ to generation $t$, the two transfers cancel each other. A similar argument applies for the debt.

Third, the allocation is state independent. This follows from the fact that full capitalization of fiscal spillovers makes intergenerational transfers impossible. As a result, regardless of the history of the economy, every generation faces the same problem.

Fourth, the institution generates a Pareto optimal allocation. This follows because voters are homogeneous - with heterogeneous agents, majority rule generally leads to sub-optimal decisions - and because, with full capitalization, voters fully internalize the fiscal spillovers generated by the DPGs. With heterogenous agents, the full capitalization result in Theorem 1 still holds, but the level of DPGs chosen need not be Pareto optimal. This failure of optimality, however, is due solely to the limitations of majority rule as a collective decision making mechanism.

Fifth, the levels of debt and land taxes are not pinned down by the model. The level of debt is irrelevant since any attempt to pass debt to future generations is fully undone by changes in the land prices. But then, consider a generation who decides to finance its expenditures on DPGs with debt, instead of land taxes. That generation pays less taxes when young, but sees the present value of land decrease 
by exactly the same amount. This allows them to postpone their taxes until the second period of their lives, but not to escape them.

The intuition behind the result is simple. Since DPGs are fully reversible, a unit of DPGs inherited from the previous generation gives the government one unit of the fully rivalrous consumption good. The commitment to use land taxes implies that a voter's claim on these resources depends on how much land he owns. In other words, the commitment to use the land tax transforms the public spillover into a private rent per-unit of land. This private rent is given by the term $-\frac{s_{G}}{L}$ in (4). These private rents shift the demand for land on a one-to-one basis: an extra unit of private rents per-unit of land increases the agent's willingness to pay for land by exactly by one unit. This shift in demand generates the full capitalization of the fiscal spillovers given by the term $\frac{s_{G}}{L}$ in (5). The intuition for the debt is similar. A unit of debt inherited from the previous generation creates a burden of $1+r$ on the government. The commitment to use the land tax transforms this burden into a negative rent per-unit of land equal to $-\frac{1+r}{L}$.

Three properties of land are essential for generating this result: (1) land is infinitely lived and sold from generation to generation, (2) land is supplied inelastically, and (3) land trades at a positive value even in the absence of intergenerational spillovers. The first property makes present generations care about capitalization effects, which is the central mechanism at work in the institutions studied in this paper. The second property is essential for the full capitalization result, and thus for optimal decision making: every unit of damage to future generations must reduce the value of land by exactly one unit. If land were supplied elastically, we would get positive but not full capitalization. For this reason we focus on land taxes, and not on property taxes. Land is supplied inelastically. Property, with its combination of land and capital, is not. The third property is essential to be able to capitalize negative fiscal spillovers like the debt: if the asset has no value, its price cannot go down in response to an increased level of debt. There is nothing special about land beyond these three properties.

Oates and Schwab (1988,1996), Glaeser (1996), and McKinnon and Nechyba (1997) have argued that interjurisdictional competition is essential to protect future generations from expropriation through the debt, and to generate incentives to invest optimally in future generations. Theorem 1 shows that this is not the case. A centralized system generates full capitalization of intergenerational fiscal spillovers 
as long as the fiscal constitution restricts the tax base to land taxes. Furthermore, as we will see in section 6 , the land tax and decentralization are not alternative mechanisms to induce full capitalization of fiscal spillovers: full capitalization of fiscal spillovers typically fails in a decentralized system with income taxation. Thus, a credible commitment through the fiscal constitution to use land taxes is the central mechanism behind the full capitalization of fiscal spillovers.

Now we provide another rationale for the debt ceiling. Given the restriction to land taxes, a debt ceiling is needed to guarantee the existence of equilibria. The debt ceiling requires $(1+r) D(s) \leq \bar{p} L$; i.e., the total fiscal burden generated by the debt must be less than the value of land (net of intergenerational spillovers). One can show that if this inequality is violated, there are states of the economy in which the aggregate demand for land is less than $L$ for any non-negative price, and thus the land market cannot clear.

We end this section with some technical comments about the result. The most important comment is that we have not been able to prove that these are the only symmetric Markovian equilibria in the infinite model, nor have we been able to construct other equilibria. We argue, however, that even if there are other equilibria, a case can be made in favor of the equilibria that we characterize. First, we know that the equilibria in Theorem 1 are the only equilibria in a finite version of the mode ${ }^{11}$ where a standard backward induction argument shows that, under our assumptions, all of the equilibria exhibit full capitalization of fiscal spillovers. (There is not a unique equilibrium because with full capitalization of fiscal spillovers the path of the debt is not pinned down). Second, any other equilibria of the infinite model would have a "bubble-like" structure: in some states the demand for land would increase, not because of a changes in the real fiscal spillovers received from the previous generation, but because changes in the state of the world would affect agent's believes about the future base-line price of land (a change in the $\bar{p}$ ). Such equilibria, if they exist, are less plausible than the equilibria characterized in Theorem 1 . In our equilibria, all that voters need to understand is that any land rents left to the

\footnotetext{
${ }^{11}$ The finite version of the model has a finite number of generations, say $T$, who live for two periods. There is a last generation $T+1$ who only lives for one period. This generation buys the land stock from generation $T$ but does not sell it to anyone else, benefits from the previous investments in IPGs but does not generate spillovers for another generation, and fulfills the debt obligations that it receives from generation $T$. Under our assumptions for $l(p)$, all of the equilibria of this model generate full capitalization as in Theorem 1, although the baseline level of land taxes and land prices $(\bar{\tau}$ and $\bar{p})$ can change with time.
} 
next generation will be incorporated into land prices through the usual forces. By contrast, the bubble-like equilibria would require agents to forecast changes in the demand for land that are not due to fundamentals and that have not been observed before. Were would such forecasts come from? This discussion on uniqueness also applies to Theorems 3,4 and 5. In each case, our results hold at every equilibrium of the finite version of the model.

We have assumed that land is not an input of production. This is not central to the result. Consider a linear aggregate production function $F\left(K, \lambda, l_{p}\right)=w \lambda+$ $(1+r) K+v l_{p}$, where $\lambda$ and $l_{p}$ denote the amount of labor and land inputs, and $K$ denotes capital. The profit maximization conditions of the firm imply that, in any equilibrium, the total price of land

$$
p^{T}(s) \equiv p(s)+\tau(s)-\frac{p((1-\delta) G(s), D(s))}{1+r}
$$

must be equal to $v$. This generates a full capitalization result identical to the one in Theorem $1 .^{12}$ Interestingly, it does not matter that firms pay land taxes even though they do not vote, or that the households only own a fraction of the land stock. With full capitalization, the total price of land is always constant and thus the amount of land purchased by the firms is also constant. Thus, the household's market and voting problems have not changed.

Finally, we have assumed that the aggregate production function takes a linear form. Consider instead a general production function $F\left(K, \lambda, l_{p}\right)$ satisfying constant returns to scale. The results in Theorem 1 hold at the steady state. The intuition is simple. With full capitalization there are no intergenerational transfers. Thus, at the steady state the savings of a generation are not affected by the public policy decisions of the pervious generation. As a result, the economy remains in the steady state. Things are more complicated outside the steady state because the problem is no longer stationary. We conjecture, but have not proven, that it is possible to extend the results to this case: there is full capitalization of fiscal spillovers, and the allocation is not affected by the previous public policy decisions.

\subsection{Direct Spillovers}

Now consider the performance of this institution when intergenerational public goods only generate direct spillovers.

\footnotetext{
${ }^{12}$ The proof in the appendix goes through with minor modifications.
} 
THEOREM 2: Consider an economy with pure IPGs, a centralized system with land taxation, and no government debt. Suppose that agents have additively separable preferences of the form $W(c, l)+Z(G)$. This institution generates a unique equilibrium of the following form:

$$
l(s)=\frac{L}{N}, G(s)=\tau(s)=0, \text { and } p(s)=\bar{p} .
$$

This allocation is not Pareto optimal: it is possible to generate a Pareto improvement that increases the level of DPGs in every period $t \geq 2$.

The performance of the institution with pure IPGs stands in stark contrast with the case of DPGs: no investment in future generations takes place. The problem is that this institution is able to capitalize fiscal spillovers, but not direct spillovers. In section 5 we show that decentralization can help in this case.

A comparison of Theorems 1 and 2 shows that the choice of land taxation to finance intergenerational programs has a profound impact in the capitalization of fiscal spillovers, but not on the capitalization of direct spillovers. The intuition for this difference is simple. Fiscal spillovers can be transformed into private rents using land taxes, direct spillovers cannot.

The no capitalization result in Theorem 2 depends on having additively separable preferences of the form $W(c, l)+Z(G)$. This is the reason. In a land market equilibrium the total price of land, as defined in (6), must be equal to the marginal rate of substitution between $c$ and $l$, given the anticipated level $G(s)$ of DPGs. With pure IPGs, $G(s)$ depends on $s$ since $G(s)=I_{t-1}$. With additive separable preferences, this does not affect the marginal rate of substitution and thus land prices. Without additive separability, a capitalization effect appears that is due, not to the direct value of the IPGs inherited from the previous generation, but to the effect of the IPGs on the marginal rate of substitution between consumption and land. Interestingly, these indirect capitalization effects can be positive or negative, and their size is not related to the value of the public goods. Thus, this type of capitalization effects are not a reliable mechanism for generating optimal investment in future generations. A similar comment applies to Theorems 3 and 5-7, were we also assume that agents have additively separable preferences. 


\section{Centralized System with Income Taxation}

Now consider a centralized institution with income taxation. Since agents are identical, and labor supply is inelastic, we model the income taxes as lump-sum taxes.

In the rest of the paper we simplify the model by assuming that the government must balance the budget every period. This is without any conceptual loss. Given that DPGs and debt only generate fiscal spillovers, adding debt has no effect on the results: every capitalization result for DPGs extends immediately to the debt.

The state of the world now is one-dimensional and given by $s \equiv s_{G}$. Let $I(s)$ denote a policy rule that specifies the level of investment in state $s$. Given this policy rule, lump-sum taxes are given by

$$
T(s) \equiv \frac{I(s)}{N} .
$$

The definition of $G(s)$ has not changed. The mapping $\sigma(s)$ is now uni-dimensional and given by

$$
\sigma(s) \equiv\left\{\begin{array}{cc}
(1-\delta)\left(s_{G}+I(s)\right) & \text { for DPGs } \\
s_{G} & \text { for pure IPGs }
\end{array} .\right.
$$

DEFINITION 2: An equilibrium for a centralized system with income taxes is given by an allocation $(l(s), G(s))$, a policy rule $I(s)$, and land prices $p(s)$ satisfying, for each $s$ :

1. Land market equilibrium:

$$
l(s) \in \arg \max _{l \geq \mathbf{0}} V\left(w-T(s)-l\left(p(s)-\frac{p(\sigma(s))}{1+r}\right), l, G(s)\right) \text { and } l(s) N=L .
$$

2. Political equilibrium: Given the land holdings $l(s)$, the land prices $p(s)$, and the capitalization function $p(\cdot), I(s)$ is a Condorcet winner in the set of feasible policies $\Pi(s){ }^{13}$

\subsection{Fiscal Spillovers}

The following result characterizes the performance of the institution when there are only fiscal spillovers:

\footnotetext{
${ }^{13}$ In this institution, a policy $I$ is feasible in state $s$ if it satisfies: (1) $I \geq-s$ in the case of DPGs, and $I \geq 0$ in the case of pure IPGs; and (2) $0 \leq T \leq w-l(s)\left[p(s)-\frac{p(\sigma)}{1+r}\right]$, where $T$ and $\sigma$ are the income tax and continuation state generated by $I$.
} 
THEOREM 3: Consider an economy with DPGs, a centralized system with income taxation, and no government debt.

(1) If agents have quasi-linear preferences of the form $W(l, G)+c$ this institution generates equilibria of the form:

$$
l(s)=\frac{L}{N}, G(s)=\bar{G}, T(s)=\bar{T}-\frac{s}{N}, \text { and } p(s)=\bar{p} ;
$$

where $\bar{G}, \bar{T}$, and $\bar{p}$ are uniquely defined constants.

The allocation generated by this equilibrium is not Pareto optimal: it is possible to generate a Pareto improvement that increases the level of DPGs in every period $t \geq 1$.

(2) If agents have Cobb-Douglas preferences of the form $c^{\alpha} l^{\beta} G^{\gamma}$, this institution generates equilibria of the form:

$$
\begin{gathered}
l(s)=\frac{L}{N}, G(s)=\bar{G}+\bar{\eta} s \\
T(s)=\bar{T}-\frac{(1-\bar{\eta}) s}{N}, \text { and } p(s)=\bar{p}+\bar{\pi} s ;
\end{gathered}
$$

where $\bar{G}, \bar{T}, \bar{p}, \bar{\pi} \in\left(0, \frac{\beta}{\alpha+\beta} \frac{1}{L}\right)$, and $\bar{\eta} \in\left(0, \frac{\gamma}{\alpha+\gamma}\right)$ are uniquely defined constants. The allocation generated by this equilibrium is not Pareto optimal: it is possible to generate a Pareto improvement that increases the level of DPGs in every period $t \geq 1$.

The first part of the result shows that with quasi-linear preferences there is no capitalization of fiscal spillovers. This necessarily generates an inefficiently low level of DPGs. The second part of the result shows that without quasi-linearity some but not full capitalization of fiscal spillovers can arise. Since $\bar{\pi}<\frac{\beta}{\alpha+\beta} \frac{1}{L}$, increasing the amount of DPGs passed to the next generation by one unit increases the value of the land stock by less than one unit. But then, present generations do not fully internalize the fiscal spillovers and the level of DPGs is inefficiently low. The mechanism behind this partial capitalization is very different from the one for land taxes: it is driven by income effects. A higher level of DPGs makes the next generation wealthier. If land is a normal good this generates a positive capitalization effect.

The result extends to the debt. With less than full capitalization intergenerational redistribution is possible and generations have an incentive to raise as much 
debt as possible. A comparison of Theorems 1 and 3 shows that in centralized systems a commitment to finance intergenerational expenditures with land taxes is essential to get full capitalization of fiscal spillovers and to avoid intergenerational expropriation through the debt.

It is important to emphasize that a commitment to finance intergenerational expenditures with land taxes is not incompatible with intragenerational redistribution. All of our capitalization results are easily extended to a world with heterogeneous agents. In that case the fiscal constitution describes a tax system with two orthogonal tiers. Tier 1 deals with intergenerational issues. Tier 2 deals with intragenerational redistribution. The two tiers are orthogonal if intergenerational expenditures are fully absorbed by the taxes in Tier 1 .

\subsection{Direct Spillovers}

Now consider the case in which there are only direct spillovers. A straightforward extension of Theorem 2 to the case of income taxation shows that, with additively separable preferences of the form $W(c, l)+Z(G)$, a centralized system with income taxation generates no capitalization of direct spillovers, and thus no investment in pure IPGs.

This, together with Theorem 2, imply that with these preferences it is not possible to generate any capitalization of direct spillovers in a centralized institution. In the next section we show that for this type of spillovers decentralization plays a crucial role.

\section{$5 \quad$ Federal System with Land Taxation}

Now consider federal systems with land taxation. The key difference between this institution and a centralized system with land taxation is that interjurisdictional competition introduces an additional capitalization mechanism. New generations prefer to move to jurisdictions with a more attractive package of intergenerational spillovers, which increases the price of land in those jurisdictions.

In a pure federal system the nation is divided into $J$ identical jurisdictions with $L_{J}=\frac{L}{J}$ units of land. Each jurisdiction decides how much to invest in a local IPG, like local public infrastructure. Let $G_{t}^{j}$ denote the level of local IPGs in period $t$ and jurisdiction $j$, and $I_{t}^{j}$ the level of investment. Since the IPGs are local, investment in 
one jurisdiction has no effect on the level of IPGs in other jurisdictions. As before, for DPGs $G_{t}^{j}=(1-\delta) G_{t-1}^{j}+I_{t}^{j}$, and for pure IPGs $G_{t}^{j}=I_{t-1}^{j}$.

Let $s_{t}=\left(s_{t}^{1}, \ldots, s_{t}^{J}\right)$ denote the state of the economy in period $t$. Given a policy rule $I^{j}(s)$ for jurisdiction $j$, land taxes are given by

$$
\tau^{j}(s) \equiv \frac{I^{j}(s)}{L_{J}}
$$

As before, let $\sigma^{j}(s)$ denote the state of jurisdiction $j$ in period $t+1$ if the state in period $t$ is $s . N^{j}(s)$ denotes the number of residents in jurisdiction $j$, and $l^{j}(s)$ the amount of land that they consume. To simplify the analysis, we do not require $N^{j}(s)=\frac{L_{J}}{l^{j}(s)}$ to take integer values. ${ }^{14}$

The notion of equilibrium for a federal system with land taxation is a natural extension of Definition 1.

DEFINITION 3: An equilibrium for a federal system with land taxation is given by an allocation $\left(N^{j}(s), l^{j}(s), G^{j}(s)\right)_{j=1}^{J}$, a policy rule $\left(I^{j}(s)\right)_{j=1}^{J}$, and land prices $\left(p^{j}(s)\right)_{j=1}^{J}$ satisfying, for each $s$ :

1. Land market equilibrium:

$$
\begin{gathered}
l^{j}(s) \in \arg \max _{l \geq 0} V\left(w-l\left(p^{j}(s)+\tau^{j}(s)-\frac{p^{j}(\sigma(s))}{1+r}\right), l, G^{j}(s)\right) \text { for all } j, \\
V\left(w-l^{j}(s)\left(p^{j}(s)+\tau^{j}(s)-\frac{p^{j}(\sigma(s))}{1+r}\right), l^{j}(s), G^{j}(s)\right)=\bar{U}(s) \text { for all } j, \\
\sum_{j} N^{j}(s)=N, \text { and } l^{j}(s) N^{j}(s)=L_{J} \text { for all } j .
\end{gathered}
$$

2. Political equilibrium: Every jurisdiction $j$, given the number of agents in the jurisdiction $N^{j}(s)$, land holdings $l^{j}(s)$, the capitalization function $p^{j}(\cdot)$, and the choices of the other jurisdictions $I^{-j}(s)$, chooses a Condorcet winner $I^{j}(s)$ in the set of feasible policies $\Pi^{j}\left(s, I^{-j}(s)\right) .{ }^{15}$

This equilibrium notion is based on the following two economic assumptions. First, there are no "locational costs" for the new generations: at the time of the land market they can purchase land in any jurisdiction and, ex-ante, the jurisdictions are

\footnotetext{
${ }^{14}$ Alternatively, we could have assumed that there is a continuum of agents.

${ }^{15}$ In this institution, $I$ is feasible in state $s$ and jurisdiction $j$ if it satisfies: (1) $I \geq-s^{j}$ in the case of DPGs, and $I \geq 0$ in the case of pure IPGs; and (2) $0 \leq \tau l^{j}(s) \leq w-l^{j}(s)\left[p^{j}(s)-\frac{p^{j}(\sigma)}{1+r}\right]$, where $\tau$ and $\sigma$ are the land tax and continuation state generated by $\left(I, I^{-j}(s)\right)$.
} 
identical. By assumption, they purchase land in at most one jurisdiction. Second, there is no short-term migration: after the generations choose where to locate, they stay there for the rest of the period. Since in this model agents die right after they sell the land in the second period of life, there is no mid-life migration. In a more realistic (but not nearly as tractable) model with multi-period lives, the definition of equilibrium would require agents to stay in the jurisdiction for the rest of the period, but not for the rest of their lives. In other words, the essence of the assumption is that agents cannot leave the jurisdiction immediately after the election: they are stuck with the outcome of the election for at least one period. In equilibrium, however, they anticipate the policies that will be enacted, and thus can move into jurisdictions that will enact their preferred policy. ${ }^{16}$

\subsection{Fiscal Spillovers}

The following result shows that the institution generates full capitalization of local fiscal spillovers.

THEOREM 4: Consider an economy with local DPGs, a federal system with land taxation, and no debt. This institution generates equilibria of the following form:

$$
\begin{gathered}
l^{j}(s)=\frac{L_{J}}{N}, G^{j}(s)=\bar{G}, \\
\tau^{j}(s)=\frac{\bar{G}}{L_{J}}-\frac{s^{j}}{L_{J}}, \text { and } p^{j}(s)=\bar{p}+\frac{s^{j}}{L_{J}} .
\end{gathered}
$$

The proof of the result is a straightforward extension of Theorem 1 and shows that interjurisdictional competition plays no role in the result. To see this, suppose that there is no mobility across the jurisdictions: each jurisdiction has $\frac{N}{J}$ agents in every period and new generations must live in the same jurisdiction than their parents. By Theorem 1, the equilibrium of this institution is the allocation and policy rule described in (8) and (9). We claim that this is also an equilibrium when there is mobility. Consider the land market first. Given the prices and policy rule, the non-mobility condition in (7) is satisfied in each state. Thus, this allocation is also a land market equilibrium when mobility is possible. Now consider the electoral

\footnotetext{
${ }^{16}$ By contrast, other authors (see Epple and Romer (1991)) assume that agents are myopic at the time of the election, but can move away right after the election. That is a natural assumption in the static framework used in that literature, but is conceptually problematic in a dynamic model since it only requires feasibility along the equilibrium path.
} 
stage. Mobility does not change the capitalization function or land holdings, and thus has no effect on the policy choice. This concludes the proof.

A comparison of Theorems 1 and 4 show that interjurisdictional competition plays no role on the capitalization of local fiscal spillovers when intergenerational expenditures are financed with land taxes. Full capitalization of fiscal spillovers takes place with or without interjurisdictional competition. This implies that there is no intergenerational case for the decentralization of policies, such as debt, that only generate fiscal spillovers. The allocation of these types of programs to the different levels of government must be based solely on other considerations like returns to scale in production and interjurisdictional spillovers. Programs that exhibit significant increasing returns to scale, such as the maintenance of a nuclear arsenal, should be allocated to the national government. By contrast, programs such as local infrastructure should be assigned to local governments. In both cases, the full capitalization result implies that present generations fully internalize the fiscal spillovers that they generate on the future.

\subsection{Direct Spillovers}

Now consider the case of direct spillovers. Thus far we have been able to provide complete and algebraic descriptions of the equilibrium allocations and policy rules. Unfortunately, we have been unable to find closed form solutions for this case. We can, however, characterize the capitalization properties of these institutions by focusing on the case of quasi-linear preferences.

Let $\bar{G}$ denote the level of IPGs produced at the symmetric steady state. Similarly, let $\bar{l}=\frac{L}{N}$ and $\bar{N}=\frac{N}{J}$ denote the amount of land consumed by each agent and the size of each jurisdiction at the symmetric steady state.

THEOREM 5: Consider an economy with pure local IPGs, a federal system with land taxation, and no government debt. Suppose that agents have preferences of the form $W(l)+\Phi(G)+c$. This institution generates equilibria in which, for all $j, k \neq j$, and all $s=\left(\bar{G}, \ldots, \bar{G}, s^{j}, \bar{G}, \ldots, \bar{G}\right)$ :

$$
\frac{\partial p^{j}(s)}{\partial s^{j}} \in\left(0, \frac{N^{j}(s) \Phi^{\prime}\left(s^{j}\right)}{L_{J}}\right) \text { and } \frac{\partial p^{k}(s)}{\partial s^{j}}<0 .
$$

A comparison of Theorems 2 and 5 show that interjurisdictional competition plays an important role in the capitalization of direct spillovers. With these types of 
preferences the centralized institution generates no capitalization. By contrast, the federal system generates a capitalization effect that is proportional to $N^{j}(s) \Phi^{\prime}\left(s^{j}\right)$, which measures the welfare impact of a marginal change in $s^{j}$ on the next generation of residents. ${ }^{17}$ However, since $L_{J} \frac{\partial p^{j}(s)}{\partial s^{j}}<N^{j}(s) \Phi^{\prime}\left(s^{j}\right)$, the institution only generates partial capitalization.

The intuition is simple. An increase in the level of IPGs in jurisdiction $j$ makes it more attractive for the new generations. This increases the demand for land in the jurisdiction and its land price. But the increased demand for jurisdiction $j$ also decreases the price of land in the other jurisdictions, increasing their attractiveness. This second force dampens the capitalization of IPGs and generates cross-jurisdictional capitalization effects: an increase in $s^{j}$ generates a negative capitalization effect in the other jurisdictions.

Given these forces, it is not surprising that the amount of under-capitalization disappears as the number of jurisdiction increases. However, this does not mean that the problem can be solved by introducing a fiscal constitutions with more jurisdictions. Public goods, like roads, exhibit decreasing returns to scale and affect residents of large geographical areas. Increases in the number of jurisdictions would improve the intergenerational incentives at the cost of introducing other sources of inefficiency. In the limit, each jurisdiction would have one agent who fully internalizes the well-being of the next generation, but who ignores the spillovers that his decisions generate on the other jurisdictions.

\section{Federal Systems with Income Taxation}

Finally consider a federal system with income taxation. $T^{j}(s)$ denotes the lump-sum tax in jurisdiction $j$ and state $s$. The definition of equilibrium is a straightforward combination of definitions 2 and 3 and thus is omitted.

Given that we are unable to provide closed from solutions for the equilibria of this institution we limit our attention to study its ability to capitalize the two types of intergenerational spillovers. To do this we consider a special case of the institution in which every jurisdiction is required to consume $G^{\prime}$ units of DPGs, in the case of fiscal spillovers, or to invest $G^{\prime}$ units in IPGs for the next generation, in the case of direct spillovers. This requirement holds in every period except $t$ where

\footnotetext{
${ }^{17}$ See the proof in the appendix for the exact formula.
} 
the jurisdictions are free to choose the level of investment.

\subsection{Fiscal Spillovers}

The following result characterizes the ability of this institution to capitalize the fiscal spillovers generated by the choice of DPGs in period $t$.

THEOREM 6: Consider an economy with local DPGs, a federal system with income taxation, no government debt, and a mandatory level of provision $G^{\prime}$ in all periods except $t$. Suppose that agents have preferences of the form $W(l, G)+$ c. Any equilibrium of this institution satisfies, for all $j$ and $k \neq j$ :

$$
\begin{gathered}
\frac{\partial p_{t+1}^{j}\left(G^{\prime}, \ldots, G^{\prime}\right)}{\partial s_{j}}=\frac{(J-1) \bar{l} W_{l l}}{J \frac{G^{\prime}}{L_{J}}+\bar{J} W_{l l}} \cdot \frac{1}{L_{J}}, \text { and } \\
\frac{\partial p_{t+1}^{k}\left(G^{\prime}, \ldots, G^{\prime}\right)}{\partial s_{j}}=-\frac{\bar{l} W_{l l}}{J \frac{G^{\prime}}{L_{J}}+J \bar{l} W_{l l}} \cdot \frac{1}{L_{J}} .
\end{gathered}
$$

This capitalization functions are rather different from the ones in Theorem 4. First, with income taxation there are cross-jurisdictional effects. Second, generically perfect capitalization does not occur. Depending on the value of $G^{\prime}$ the institution can generate partial capitalization (if $G^{\prime}$ is small enough), more than $100 \%$ capitalization (for intermediate values of $G^{\prime}$ ), and even negative capitalization (if $G^{\prime}$ is large enough). In this result $G^{\prime}$ is a parameter of the fiscal constitution. However, the result is also of interest for the full blown institution since it is possible to choose parameters that generate any level of DPGs along the equilibrium path, and thus any of these 3 cases. For example, it is possible to choose parameters such that the steady state level of DPGs is large, in absolute terms, but also inefficiently low because there is negative capitalization in equilibrium.

The intuition for the stark difference between land and income taxation goes as follows. Regardless of the tax base, we can think of government policy as taking place in two stages. First, the government returns all the fiscal spillovers received from the previous generation to the citizenry. Second, it raises enough revenue to pay for the DPGs that it wants to consume. By design, the choice of DPGs in period $t+1$ is fixed and equal to $G^{\prime}$. To pay for this every jurisdiction needs to raise $G^{\prime}$ units of revenue. The capitalization effects in the land market change the number of residents who live in each jurisdiction. With land taxation this has no effect on the tax per-unit of land that the residents pay. With income taxation, by contrast, 
lump-sum taxes decrease as agents move into the jurisdiction. This introduces an additional force: it makes jurisdiction $j$ even more attractive. If $G^{\prime}$ is large enough this effect dominates and the only way the non-mobility condition in (7) can be satisfied is if agents move out of jurisdiction $j$ in response to an increase in $s^{j}$. This generates a negative capitalization effect. In this case the utility of living in every jurisdiction goes up: in jurisdiction $j$ because of the additional IPGs received from the past, in the other jurisdictions because the lump-sum taxes needed to pay for $G^{\prime}$ go down.

A comparison of Theorems 1, 4 and 6 show that interjurisdictional competition and land taxation are not alternative mechanisms for generating perfect capitalization of fiscal spillovers. The use of land taxes transforms the fiscal spillovers into private rents and thus generates perfect capitalization with or without interjurisdictional competition. By contrast, interjurisdictional competition without land taxation can generate over, under, and even negative capitalization.

\subsection{Direct Spillovers}

Finally consider the performance of this institution when there are only direct spillovers.

THEOREM 7: Consider an economy with pure local IPGs, a federal system with income taxation, a mandatory level of investment $G^{\prime}$ in all periods except $t$, and no government debt. Suppose that agents have preferences of the form $W(l)+\Phi(G)+c$. Any equilibrium of this institution satisfies, for all $j, k \neq j$, and all $s=\left(G^{\prime}, \ldots, G^{\prime}, s^{j}, G^{\prime}, \ldots, G^{\prime}\right)$ :

$$
\begin{aligned}
\frac{\partial p^{j}(s)}{\partial s^{j}} & =\frac{\frac{(J-1) l^{j} W_{l l}^{j}}{\left(l_{k}\right)^{2}}}{\frac{(J-1) \bar{G}}{L_{J}\left(l^{k}\right)^{2}}+\frac{\bar{G}}{L_{J}\left(l^{j}\right)^{2}}+\frac{(J-1) l^{j} W_{l l}^{j}}{\left(l^{k}\right)^{2}}+\frac{l^{k} W_{l l}^{k}}{\left(l^{j}\right)^{2}}} \frac{N^{j}(s) \Phi^{\prime}\left(s^{j}\right)}{L_{J}}, \text { and } \\
\frac{\partial p^{k}(s)}{\partial s^{j}} & =-\frac{\frac{l^{k} W_{l l}^{k}}{\left(l^{j}\right)^{2}}}{\frac{(J-1) \bar{G}}{L_{J}\left(l^{k}\right)^{2}}+\frac{\bar{G}}{L_{J}\left(l^{j}\right)^{2}}+\frac{(J-1) l^{j} W_{l l}^{j}}{\left(l^{k}\right)^{2}}+\frac{l^{k} W_{l l}^{k}}{\left(l^{j}\right)^{2}}} \frac{N^{k}(s) \Phi^{\prime}\left(s^{j}\right)}{L_{J}} .
\end{aligned}
$$

These capitalization functions are rather different from the ones generated by a pure federal system with land taxation. Land taxation always generates undercapitalization. By contrast, depending on the size of $G^{\prime}$, income taxation can generate partial capitalization (if $G^{\prime}$ is small enough), more than $100 \%$ capitalization (for 
intermediate values of $G^{\prime}$ ), and even negative capitalization (if $G^{\prime}$ is large enough). The intuition for this result is identical to the one for Theorem 7 .

A comparison of Theorems 2, 5, and 7 show that there is an intergenerational case for decentralization. However, it is significally weaker than the one that has been made by Oates and Schwab (1988,1996), Glaeser (1996), and McKinnon and Nechyba (1997). First of all, it only applies for intergenerational expenditures that generate a disproportionate amount of direct spillovers, generate a small amount of interjurisdictional spillovers, and exhibit limited returns to scale in production. Irreversible local environmental damage is an example of such an expenditure. The debt, protection of national parks, and public infrastructure are not. Second, decentralization is not a sufficient policy instrument: the choice of the tax base is crucial. The use of land taxation always generate positive, but not full capitalization. By contrast, income taxes can generate under, over, and negative capitalization; with perfect capitalization being the exception rather than the rule. This constitutes a choice between second best policy instruments. Each tax base dominates the other for some public goods.

\section{Conclusion: How to Design an Intergenerational Fis- cal Constitution}

This paper has studied how to design a fiscal constitution that, by capitalizing intergenerational spillovers into land values, is able to protect future generations from expropriation and to generate optimal investment in IPGs. In particular, we have studied how to accomplish these goals by changing two dimensions of the fiscal constitution: (1) the level of government to which different types of IPGs are assigned, and (2) the tax base of the different jurisdictions.

We have shown that the instruments required to generate capitalization of the intergenerational spillovers depend on the type of the spillover. Land taxation is the essential instrument for policies that mostly generate fiscal spillovers, such as debt and public infrastructure. By contrast, interjurisdictional competition is the essential instrument for policies that mostly generate direct spillovers, such as irreversible environmental damages. We have also shown that it is possible to design a fiscal constitution that generates full capitalization of fiscal spillovers, but in general, not one that generates full capitalization of direct spillovers.

Our results provide the following guidelines for how to design a fiscal constitution 
that is intergenerationally friendly:

- Implement a mixed federal system that includes a national government and multiple tiers of decentralization (states, counties, and localities) and introduce policy-specific restrictions on the tax base of each jurisdiction.

- To avoid intergenerational redistribution using the debt, require every government unit to finance all debt service using its own land taxes.

- Allocate DPGs to the lowest level of government that internalizes all interjurisdictional spillovers and exhausts the returns to scale in production. Finance DPGs only with land taxes: any transfer of resources between the government and the citizenry that results from the purchase or sale of a DPG must be made using land taxes (or subsidies). This implies that national infrastructure, R\&D, and national forests are assigned to the federal government and financed with a federal land tax. Local infrastructure is assigned to local governments and financed with local land taxes.

- Local IPGs that generate significant direct intergenerational spillovers, like local irreversible environmental decisions, are decentralized.

- IPGs that generate direct spillovers, but also significant amount of interjurisdictional spillovers (or that exhibit returns to scale in production) are treated differently. In this case, the allocation of the programs to jurisdictions depends on the relative size of two forces: the provision of intergenerational incentives, which calls for decentralization, and the internalization of interjurisdictional spillovers, which calls for centralization. For example, in the case of the preservation of endangered species the interjurisdictional spillovers are likely to be dominant, which calls for centralization. By contrast, in the case of state parks, which generate some interjurisdictional spillovers but are consumed mostly by state residents, the provision of intergenerational incentives dominates.

The fiscal constitution described here provides an alternative to the imposition of budget rules and capital accounting. ${ }^{18}$ These rules are common in the US and restrict the circumstances under which the government can issue debt. For example, in some jurisdictions debt is allowed only for "capital investing". In principle, this

\footnotetext{
${ }^{18}$ See the Report of the President's Commission to Study Capital Budgeting (1999).
} 
allows present and future generations to share the costs of providing IPGs, but it rules out intergenerational expropriation. The problem with these types of rules is that it is hard to distinguish capital from non-capital public goods because most durable public good benefits present and future generations. Also, these rules typically do not preclude the introduction of pay-as-you-go social insurance systems that are equivalent to issuing debt. Both problems limit the effectiveness of the institution. By contrast, the fiscal constitution specified here does not restrict the ability of the government to issue debt (expect, perhaps, for a large total debt ceiling). And yet, it accomplishes the goal that motivates the use of budgetary rules: intergenerational expropriation is not possible and future generations repay present generations for the spillovers that they receive (fully in the case of fiscal spillovers and partially in the case of direct spillovers).

\section{Appendix: Proofs}

Proof of Theorem 1: (Step 1) Consider a static version of our land market. $L$ units of land are supplied inelastically by exogenous land owners. There are $N$ identical agents with preferences given by (1) and wealth $w$. The level of the parameter $G$ is fixed exogenously and there are no taxes. We claim that there is a unique land price $p^{*}(G)$ that clears this market. The properties of $V($. imply that $l(p)$ is continuous, $l(p) \rightarrow 0$ as $p \rightarrow \infty$, and $l(p) \rightarrow \infty$ as $p \rightarrow 0$. Furthermore, by assumption $l(p)$ is decreasing, and strictly decreasing at any $l>0$. This implies that there exists a unique $p^{*}(G)$ such that $N l\left(p^{*}(G)\right)=L$.

(Step 2) Now we show that the land prices in (5) clear the land market in every state $s$. Let $p^{T}(s)$ denote the total cost of a unit of land in state $s$, which is given by

$$
p^{T}(s) \equiv p(s)+\tau(s)-\frac{p((1-\delta) G(s), D(s))}{1+r} .
$$

In the land market agents take as given the outcome of future elections and the capitalization function given in (5). As a result, land market clearing requires $p^{T}(s)=p^{*}(G(s))$ for all $s$. Substituting the values of $(4), G(s)=\bar{G}$, and

$$
p((1-\delta) G(s), D(s))=\bar{p}+\frac{(1-\delta) \bar{G}}{L}-\frac{(1+r)\left(s_{D}+\Delta(s)\right)}{L}
$$

we get that

$$
p(s)=\left[p^{*}(\bar{G})-\frac{\bar{G}}{L}+\frac{\bar{p}}{1+r}+\frac{(1-\delta) \bar{G}}{(1+r) L}\right]+\frac{s_{G}}{L}-\frac{(1+r) s_{D}}{L} .
$$


Thus, the prices in (5), with

$$
\bar{p}=\frac{1+r}{r}\left(p^{*}(G)-\frac{(r+\delta) \bar{G}}{(1+r) L}\right),
$$

clear the market in every state $s$.

(Step 3) Now consider the election stage. At this stage agents take as given the capitalization function in (5) and their land holdings $l(s)=\frac{L}{N}$. We need to show that, for every state $s,(I(s), D(s))$, with $I(s)=\bar{G}-s_{G}$ is a Condorcet winner on $\Pi(s)$. It is useful to relabel the policy space in terms of changes in the debt $\Delta$ and desired level of DPGs. The preferences of the representative agent over $(\Delta, G)$ are given by

$$
V\left(w-\frac{L}{N} \mu(s, \Delta, G), \frac{L}{N}, G\right),
$$

where

$$
\mu(s, \Delta, G)=p(s)+\frac{G-s_{G}+r s_{D}-\Delta}{L}-\frac{p\left((1-\delta) G, s_{D}+\Delta\right)}{1+r} .
$$

Note that this specification assumes that the DPGs are reversible, since we have not restricted the second term to be positive. Substituting the value of $p(s)$ we get that

$$
\mu(s, \Delta, G)=\frac{r \bar{p}}{1+r}+\frac{G}{L}-\frac{(1-\delta) G}{(1+r) L},
$$

which is state independent and is not affected by $\Delta$. Then, the strict concavity properties of $V$ guarantee that there is a unique $\bar{G}$ such that any feasible pair $(\Delta, \bar{G})$ is a Condorcet winner.

(Step 4) Finally we show that the institution generates an allocation that is Pareto optimal. Since the economy is dynamically efficient, any inefficiency must be due to the level of DPGs. Thus, without loss of generality, we can focus on the case in which there is no debt.

Consider the stationary allocation that arises when all of the fiscal spillovers produced by the period $t$ DPG are returned to generation $t$ and, given this, generations invest optimally in the DPG. The level of DPGs in this allocation is given by

$$
G=\arg \max _{G \geq \mathbf{0}} V\left(w-\frac{G}{N}+\frac{(1-\delta) G}{(1+r) N}, \frac{L}{N}, G\right)
$$


Clearly, since the economy is dynamically efficient, this allocation must be Pareto optimal. (Recall that for DPGs the spillovers are reversible). But this is the same allocation generated by the institution.

Proof of Theorem 2: (Step 1) By the same argument used in step 1 of the previous proof, let $p^{*}(G)$ be the unique price that clears the static version of the land market. With preferences of the form $W(c, l)+Z(G)$ we must have that $p^{*}(G)=p^{*}$. It is straightforward to show that if $\bar{p}=\frac{1+r}{r} p^{*}$ the market clears in every state.

(Step 2) Now consider the electoral stage. $\tau=0$ is the unique Condorcet winner in every stage since prices are state independent and $\tau$ does not affect the level of IPGs consumed by the generation paying the taxes.

(Step 3) Consider a move from the equilibrium allocation to the following allocation: every generation $t \geq 1$ invests $\varepsilon$ in the IPG, and $\rho$ units of the private good are transferred from each generation $t \geq 2$ to each generation $t-1$. This improves the welfare of generation 1 as long as $\rho>\varepsilon(1+r)$. By the Inada conditions, $\frac{\partial V\left(w-x, \frac{L}{N}, x\right)}{\partial G} \rightarrow \infty$ as $x \rightarrow 0$. Thus, as long as $\rho$ and $\varepsilon$ are sufficiently small, every generation $t \geq 2$ is also better off.

\section{Proof of Theorem 3:}

Part 1: (Step 1) Let $p^{*}(G)$ denote the market clearing price in a static economy, as defined in Step 1 of the proof of Theorem 1. Given the quasi-linear of preferences, $p^{*}(G)$ does not depend on the wealth of the agent.

(Step 2) It is straightforward to check that if $\bar{p}=\frac{1+r}{r} \bar{G}$ the land market clears in every state $s$.

(Step 3) Consider the election in state $s$. The problem of the representative agent can be written as

$$
\max _{G \geq \mathbf{0}} W\left(\frac{L}{N}, G\right)+w+\frac{s}{N}-\frac{G}{N}-\frac{L}{N} \bar{p} .
$$

As long as $w$ is large enough, the solution is interior for every $s$ and state independent. By the properties of the utility function the solution, denoted by $\bar{G}$, is unique. The form of the tax function follows directly.

(Step 4) The FOCs for (10) are given by $N W_{G}=1$. But then, it is possible to construct a Pareto improvement by increasing the level of DPGs in every 
$t \geq 1$ by a marginal amount $\varepsilon$. Each increase leaves generation $t$ first-order indifferent, and in addition generates $\frac{1-\delta}{1+r}$ units of resources, measured in period $t$ prices, that can be used to make each generation $t$ better off.

Part 2: (Step 1) Let $p_{I}^{T}(s) \equiv p(s)-\frac{p(\sigma(s))}{1+r}$ denote total land prices for this institution. Given that preferences are Cobb-Douglas, in equilibrium we must have that

$$
\frac{L}{N}=\frac{\beta}{\alpha+\beta} \frac{1}{p_{I}^{T}(s)}\left(w+\frac{s}{N}-\frac{G(s)}{N}\right) .
$$

Which implies that, for all $s$,

$$
p(s)-\frac{p((1-\delta) G(s))}{1+r}=\frac{\beta}{\alpha+\beta} \frac{N}{L}\left(w+\frac{s}{N}-\frac{G(s)}{N}\right) .
$$

(Step 2) Consider the election in stage $s$. The representative agent solves

$$
G(s)=\arg \max _{G \geq 0} \gamma \log (G)+\alpha \log \left(w-\frac{L}{N} p(s)+\frac{s}{N}-\frac{G}{N}-\frac{L}{N} \frac{p((1-\delta) G)}{1+r}\right) .
$$

(Step 3) Now we show that there are constants $\bar{p}, \bar{G}, \bar{\pi} \in\left(0, \frac{\beta}{\alpha+\beta} \frac{1}{L}\right)$ and $\bar{\eta} \in\left(0, \frac{\gamma}{\alpha+\gamma}\right)$ such that $p(s)=\bar{p}+\bar{\pi} s$ and $G(s)=\bar{G}+\bar{\eta} s$ satisfy (11) and (12) for all $s$. To show this suppose that the solution has this form.

For (11) to be satisfied for all $s$ it must be the case that

$$
\bar{\pi}\left[1-\frac{(1-\delta) \bar{\eta}}{1+r}\right]=\frac{1-\bar{\eta}}{L} \frac{\beta}{\alpha+\beta}
$$

and

$$
\bar{p}=\frac{1+r}{r}\left[\frac{N}{L} \frac{\beta}{\alpha+\beta}\left(w-\frac{\bar{G}}{N}\right)+\frac{(1-\delta) \bar{\pi}}{1+r} \bar{G}\right] .
$$

Let $\pi^{1}(\bar{\eta})$ denote the locus implicitly defined by (13). It is easy to check that it passes through $\left(0, \frac{\beta}{\alpha+\beta} \frac{1}{L}\right)$ and $(1,0)$, is concave, and negatively slopped in the first quadrant.

For (12) to be satisfied for all $s$ it must be the case that

$$
\bar{\eta}=\frac{\gamma}{\alpha+\gamma} \frac{(1-L \bar{\pi})}{1-\frac{(1-\delta) \bar{\pi} L}{1+r}} .
$$

and

$$
\bar{G}=\frac{\gamma}{\alpha+\gamma} \frac{\left(w-\frac{L}{N} \frac{r \bar{p}}{1+r}\right)}{1-\frac{(1-\delta) \bar{\pi} L}{1+r}}
$$

Let $\pi^{2}(\bar{\eta})$ denote the locus implicitly defined by (14). It is easy to check that it passes through $\left(0, \frac{1}{L}\right)$ and $\left(\frac{\gamma}{\alpha+\gamma}, 0\right)$, is linear, and negatively slopped. 
Any intersection of $\pi^{1}(\bar{\eta})$ and $\pi^{2}(\bar{\eta})$ satisfying $\bar{\pi} \in\left(0, \frac{\beta}{\alpha+\beta} \frac{1}{L}\right)$ and $\bar{\eta} \in\left(0, \frac{\gamma}{\alpha+\gamma}\right)$ defines an equilibrium. The properties of $\pi^{1}(\bar{\eta})$ and $\pi^{2}(\bar{\eta})$ imply that there is a unique solution in this range.

(Step 4) Note that the problem of the representative voter generates first order conditions

$$
N \frac{V_{G}}{V_{c}}=1-L \bar{\pi} \frac{(1-\delta)}{1+r} .
$$

Since $\bar{\pi}<\frac{1}{L}$, an argument similar to the one in the fourth Step for Part 1 shows that it is possible to generate a Pareto improvement by increasing the level of DPGs in every period.

Proof of Theorem 5: (Step 1) We show that there is an equilibrium in which investment in pure local IPGs is state independent. The voting problem of the representative agent in jurisdiction $j$ and state $s$ is given by

$$
\max _{G^{j} \geq \mathbf{0}} w-l^{j}(s) p^{j}(s)+\left(\frac{p^{j}\left(G^{j}, G^{-j}\right)}{1+r}-\frac{G^{j}}{L_{J}}\right) l^{j}(s),
$$

where $G^{-j}$ denotes the anticipated choices of the other jurisdictions. The $G^{j}$ that solves this problem is state independent as long as $G^{-j}$ is also state independent. Then there is a symmetric equilibrium in which the level of investment in each jurisdiction, call it $\bar{G}$, is state independent.

(Step 2) Consider the land prices in period $t$ when the state of the world is $s=\left(\bar{G}, \ldots, \bar{G}, s^{j}+\theta, \bar{G}, \ldots, \bar{G}\right)$. Let

$$
\hat{p}^{j}(s)=p^{j}(s)-\frac{p^{j}(\bar{G}, \ldots, \bar{G})}{1+r}
$$

denote the pre-tax cost of housing in period $t$ and state $s$. Given step 1 , the symmetric land market equilibrium in period $t$ is fully characterized by the following four equations (where $k$ denotes any jurisdiction other than $j$ ):

$$
\begin{gathered}
W\left(l^{j}(s)\right)+\Phi\left(s^{j}+\theta\right)+w-\frac{\bar{G}}{L_{J}} l^{j}(s)-\hat{p}^{j}(s) l^{j}(s) \\
=W\left(l^{k}(s)\right)+\Phi(\bar{G})+w-\frac{\bar{G}}{L_{J}} l^{k}(s)-\hat{p}^{k}(s) l^{k}(s), \\
\frac{\partial W\left(l^{j}(s)\right)}{\partial l}=\hat{p}^{j}(s)+\frac{\bar{G}}{L_{J}}, \\
\frac{\partial W\left(l^{k}(s)\right)}{\partial l}=\hat{p}^{k}(s)+\frac{\bar{G}}{L_{J}},
\end{gathered}
$$


and

$$
\frac{L_{J}}{l^{j}(s)}+(J-1) \frac{L_{J}}{l^{k}(s)}=N .
$$

(Step 3) Note that $\frac{\partial \widehat{p}^{j}(s)}{\partial s^{j}}=\frac{\partial p^{j}(s)}{\partial s^{j}}$. Treating $\theta$ as a parameter, applying the implicit function theorem, and evaluating at $\theta=0$ we get that:

$$
\begin{gathered}
\frac{\partial p^{j}(s)}{\partial s^{j}}=\frac{\frac{(J-1) l^{j} W_{l l}^{j}}{\left(l_{k}\right)^{2}}}{\frac{(J-1) l^{j} W_{l l}^{j}}{\left(l^{k}\right)^{2}}+\frac{l^{k} W_{l l}^{k}}{\left(l^{j}\right)^{2}}} \frac{N^{j}(s) \Phi^{\prime}\left(s^{j}\right)}{L_{J}}, \text { and } \\
\frac{\partial p^{k}(s)}{\partial s^{j}}=-\frac{\frac{l^{k} W_{l l}^{k}}{\left(l^{j}\right)^{2}}}{\frac{(J-1) l^{j} W_{l l}^{j}}{\left(l^{k}\right)^{2}}+\frac{l^{k} W_{l l}^{k}}{\left(l^{j}\right)^{2}}} \frac{N^{k}(s) \Phi^{\prime}\left(s^{j}\right)}{L_{J}} .
\end{gathered}
$$

The properties of this derivatives then follow from $W_{l l}^{j}, W_{l l}^{k}<0$.

Proof of Theorem 6: The proof is almost identical to the proof of Theorem 5 and thus is omitted. There are only two differences. First, (15) is now given by

$$
\begin{aligned}
& W\left(l^{j}(s), G^{\prime}\right)+w-\frac{\left(G^{\prime}-\theta\right)}{L_{J}} l^{j}(s)-\hat{p}^{j}(s) l^{j}(s) \\
= & W\left(l^{k}(s), G^{\prime}\right)+w-\frac{G^{\prime}}{L_{J}} l^{k}(s)-\hat{p}^{k}(s) l^{k}(s),
\end{aligned}
$$

and equations (16) and (17) in the system now become

$$
\frac{\partial W\left(l^{j}(s)\right)}{\partial l}=\hat{p}^{j}(s) \text { and } \frac{\partial W\left(l^{k}(s)\right)}{\partial l}=\hat{p}^{k}(s) .
$$

Second, the first step of the proof is not needed since by construction, the level of local DPGs in period $t+1$ must be equal to $G^{\prime}$. This implies that the properties derived in this theorem hold at every equilibrium.

Proof of Theorem 7: The proof is almost identical to the proof of Theorem 5 and thus is omitted. There a only two differences. First, equations (16) and (17) in the system now become

$$
\frac{\partial W\left(l^{j}(s)\right)}{\partial l}=\hat{p}^{j}(s) \text { and } \frac{\partial W\left(l^{k}(s)\right)}{\partial l}=\hat{p}^{k}(s) .
$$

Second, the first step of the proof is not needed since by construction, the level of investment in pure local IPGs in period $t+1$ must be equal to $G^{\prime}$. This implies that the properties derived in this theorem hold at every equilibrium. 


\section{References}

[1] Altonji, L., F. Hayashi, and L. Kotlikoff (1992) "Is the Extended Family Altruistically Linked? Direct Tests Using Micro Data," American Economic Review, December, 1177-98.

[2] Altonji, L., F. Hayashi, and L. Kotlikoff (1997) "Parental Altruism and Inter Vivos Transfers: Theory and Evidence," Journal of Political Economy, December, 1121-66.

[3] Boldrin, Michele and Ana Montes (1998) "Intergenerational Transfer Institutions: Public Education and Public Pensions," University of Minnesota, manuscript.

[4] Brueckner, Jan and Man-Soo Joo (1991) "Voting with Capitalization," Regional Science and Urban Economics, 21, 453-67.

[5] Epple, Dennis and Thomas Romer (1991) "Mobility and Redistribution," Journal of Political Economy, 99, 828-58.

[6] Epple, D. and K. Schipper (1981) "Municipal Pension Funding: A Theory and Some Evidence," Public Choice, 37, 141-78.

[7] Glaeser, Edward (1996) "The Incentive Effects of Property Taxes on Local Governments," Public Choice, 89, 93-111.

[8] Inman, Robert (1982) "Public Employee Pensions and the Local Labor Budget," Journal of Public Economics, 19, 49-71.

[9] Inman, Robert (1990) "Public Debts and Fiscal Politics: How to Decide?", American Economic Review Papers and Proceedings, 80, 81-5.

[10] Inmand, Robert and Daniel Rubinfeld (1996) "Designing Tax Policy in Federalist Economies: An Overview," Journal of Public Economics, 60, 307-34.

[11] Johnson, R. (1997) "Pension Underfunding and Liberal Retirement Benefits Among State and Local Government Workers," National Tax Journal, 50, 11339.

[12] Kotlikoff, Larry and Robert Rosenthal (1993) "Some Inefficiency Implications of Generational Politics and Exchange," Economics and Politics, 5, 27-42. 
[13] McKinnon, Ronald. and Thomas Nechyba (1997) "Competition in Federal Systems: The Role of Political and Financial Constraints," in The New Federalism: Can the States Be Trusted?, John Ferejohn and Barry Weingast (eds.), Hoover Press, 1-55.

[14] Mumy, G. (1978) "The Economics of Local Government Pensions and Pension Funding," Journal of Political Economy, 86, 517-27.

[15] Oates, Wallace (1999) “An Essay on Fiscal Federalism," Journal of Economic Literature, 37, 1120-49.

[16] Oates, Wallace, and Robert Schwab (1988) "Economic Competition Among Jurisdictions: Effficiency Enhancing or Distortion Inducing?", Journal of Public Economics, 35, 333-54.

[17] Oates, Wallace, and Robert Schwab (1996) "The Theory of Regulatory Federalism: The Case of Environmental Management," in The Economics of Environmental Regulation, W. Oates (ed.), Cheltenham,UK: Edward Elgar Publishing Limited.

[18] Rangel, Antonio (2001) "Forward and Backward Intergenerational Goods: Why is Social Security Good for the Environment?", Stanford manuscript.

[19] Report of the President's Commission to Study Capital Budgeting. Washington D.C., 1999.

[20] Rubinfeld, Daniel (1987) "The Economics of the Local Public Sector," in Auerbach and Feldstein (eds.) Handbook of Public Economics, vol. II, Elsvier Science Publishers.

[21] Skinner, Jonathan (1991) "Prospects for Agricultural Land Taxation in Developing Countries," The World Bank Economic Review, 5, 493-511.

[22] Sprunger, Philip and John Wilson (1998) "Imperfectly Mobile Households and Durable Public Goods: Does the Capitalization Mechanism Work?", Journal of Urban Economics, 44, 468-92.

[23] Wildasin, David (1986). Urban Public Finance. Hardwood Academic Publishers. 
[24] Wildasin, David and John Wilson (1996) "Imperfect Mobility and Local Government Behavior in an Overlapping Generations Model," Journal of Public Economics, 60, 177-90. 